\title{
The study of technology acceptance for e-wallets application of clinic fees payment
}

\author{
Yi-Horng Lai \\ Department of Health Care Administration, Oriental Institute of Technology, Taipei, Chinese Taipei; FL006@mail.oit.edu.tw
}

Received 31 August 2012; revised 7 October 2012; accepted 17 October 2012

\section{ABSTRACT}

The purpose of this study was to investigate the demand of application of e-wallet in domestic retail industry by examining the needs of adoption of small amount paying method and the reasons for customers' using of IC stored value card in this industry and aimed at providing suggestions on the e-development of small amount paying methods for domestic retail and banking industries. This study was developed in a way that the model constructs in TAM were adapted to the context of using e-wallets for clinic fees. Scale items on the survey include those measuring perceived usefulness, perceived ease of use, a user's attitude toward using and intention. The questionnaire contains no identifying information about the individual participants. A total of $\mathbf{3 2 0}$ Taipei City Hospital patients' feedbacks were collected. Results indicate most of the relationships in the pro-posed model are statistically significant and in the predicted directions. Each observed variables influence with two ways: direct effect and indirect effect, and the total effect is the sum of direct effect and indirect effect. The Main effect of most of these observed variables is direct effect, but the information technology experience with the perceived usefulness. In this study, it could be finding that the perceived usefulness, the perceiver ease of use is positively associated with users' attitude toward using, and the perceiver ease of use is positively associated with the perceived usefulness. It means the useful and easily operation of payment clinic fees with e-wallet products (such as Taipei Easy Card) is very important for the users. Besides, the easier for e-wallet using, the more people think it is usefulness. This suggestion is the same as the point at issue of Davis [1]. The users' attitude toward using is positively associated with the intention using.

Keywords: E-Wallets; Clinic Fees; Information Technology Experience

\section{INTRODUCTION}

In recent years, the development and commercial application of e-wallets have shown promising growth in the industries of transportation, telecommunication, etc. As for in the retail industry, paying by cash is still the dominant method, especially in the convenience stores, huge quantity of transactions with small amount makes payment via credit card or cash card inconvenient. The application of paying via low-cost IC card with the aims of security and convenience will bring great benefit to the business and the customers alike.

The purpose of this study was to investigate the demand of application of e-wallet in domestic retail industry by examining the needs of adoption of small amount paying method and the reasons for customers' using of IC stored value card in this industry and aimed at providing suggestions on the e-development of small amount paying methods for domestic retail and banking industries.

The report starts with the introduction to easy card with credit option and the commercial applications of IC card, and then goes on to the research of demands of customers, retail industry and baking sector. Finally the report leads to the results of the questionnaire investigating the effects of variables of population poll and life style on the adoption of easy card/e-money.

\subsection{An E-Wallet: Taipei Easy Card}

When consumers shopping with small payment, it is inconvenient that pay by credit card or cash in the transaction process. For this reason, one micro-payment way to be built now, it is called e-wallet. Bank for International Settlements (BIS) define e-wallet is stored in the consumer's electronic equipment, as money-stored or pre-paid tools [2]. E-wallet is an IC chip plastic cards, 
and cardholder can pay with it.

Taipei Easy Card is an e-wallet that provided by Easy Card Corporation. It is a non-contact multi-function electronic ticket integration of the payment of the Taipei mass rapid transit system, buses, parking, and authorized stores. Users pass the card over the sensor area to make a transaction, avoiding hassles with finding correct change. As value can be added to the card at any time, there is no need to repeatedly purchasing new cards. Taipei Easy Card can be used for years and its ultimate aim is to allow people to travel throughout Taiwan with only one card.

People to hospitals for treatment, has a money card chargeback equipment at direct induction debit, to complete the registration fees and medical expenses to pay, eliminating the need for site preparation cash or exchange the inconvenience of looking for change after August, 2008. The object of this study is finding the influence of the active of using Easy Card for clinic fees.

\subsection{The Technology Acceptance Model}

Based on the theory of reasoned actions (TRA) [3], TAM addresses factors influencing a user's attitude toward using (ATT) and intention to use technology [1]. TAM has been widely adopted in studies exploring technology acceptance due to its parsimonious nature and highly reliable constructs. Examples include studies testing user acceptance of word processors [1], spreadsheet applications [4], email [5], and websites [6].

TAM considers perceived usefulness (PU) and perceived ease of use (PE) as two major factors influencing a user's attitude toward using technology (ATT). The former refers to the perceived effectiveness of improving the user's performance, while the latter refers to how effortless a user perceives using the technology to be. Prior research has found that PE mostly influences attitude and intention indirectly through PU [7]. Perceived usefulness and user attitude in turn influence intention to use, which predicts actual usage of technology. Treating the application of e-wallets as a new technology is used in Hospital in Hong Kong. This paper proposes that the same relationships from TAM hold in relation to pay clinic fees with Taipei Easy Card.

H1: PE is positively associated with ATT.

H2: PU is positively associated with ATT.

H3: PE is positively associated with PU.

H4: ATT is positively associated with Intention.

$\mathrm{H} 5$ : PU is positively associated with Intention.

\subsection{Personal Prior Experience}

Experience was not explicitly included in the original TAM. Davis [3] and consumer behavior researchers has studied the relationship between a person's experiences and his or her behavior. Experience, which is the result of acquiring and processing stimulation over time, is one factor that determines how much exposure to a particular stimulus a person accepts.

Peter and Olson point out that "Personal experience of a given object affects a person's behavior” [8]. They found that the more positive a person's experience about an object is, the more positive beliefs he or she will hold about it. As a result, the more positive beliefs a person has, the more positive attitude this will create. On the other hand, according to the user behavior literature, beliefs and attitudes are principally created based on a person's personal experience of a given object.

Prior information technology experience (TE) influences the attitude and performance of using technical devices [9]. Generally, it has found that experts show a superior performance with respect to the utilization of technology. This finding is rather trivial as long as the relationship between computer experience, technology acceptance, and performance is not completely clarified.

Thompson, Higgins, and Howell [10] argued that within the context of information technology, both self-reported computer skill and length of use should be measured because they represent distinct dimensions of general computer experience. As a reflection of selfreported computer skill, computer self-efficacy measures the level of confidence that a user has when working with new software packages. On the other hand, the length of computer experience is an objective measure of a user's computer experience. More computer experience usually implies greater exposure to different types of applications and higher level of familiarity with various software packages. Although computer expertise and its effect on performance has been studied thoroughly [9], the underlying concept of expertise and its measurement are not exactly defined yet. This expectation leads to the hypothesis:

H6: TE is positively associated with PU.

H7: TE is positively associated with PE.

\section{METHOD}

With PE, PU and related propositions integrated, Figure 1 summarizes the research framework of this study in a TAM model in which perceived ease of use, perceived usefulness, information technology experience and medical treatment experience positively influence users' attitude and intentions.

\subsection{Methodology}

The validity of the proposed relationships in the research model presented above was investigated through a field study. This study incorporated use of wallets for 


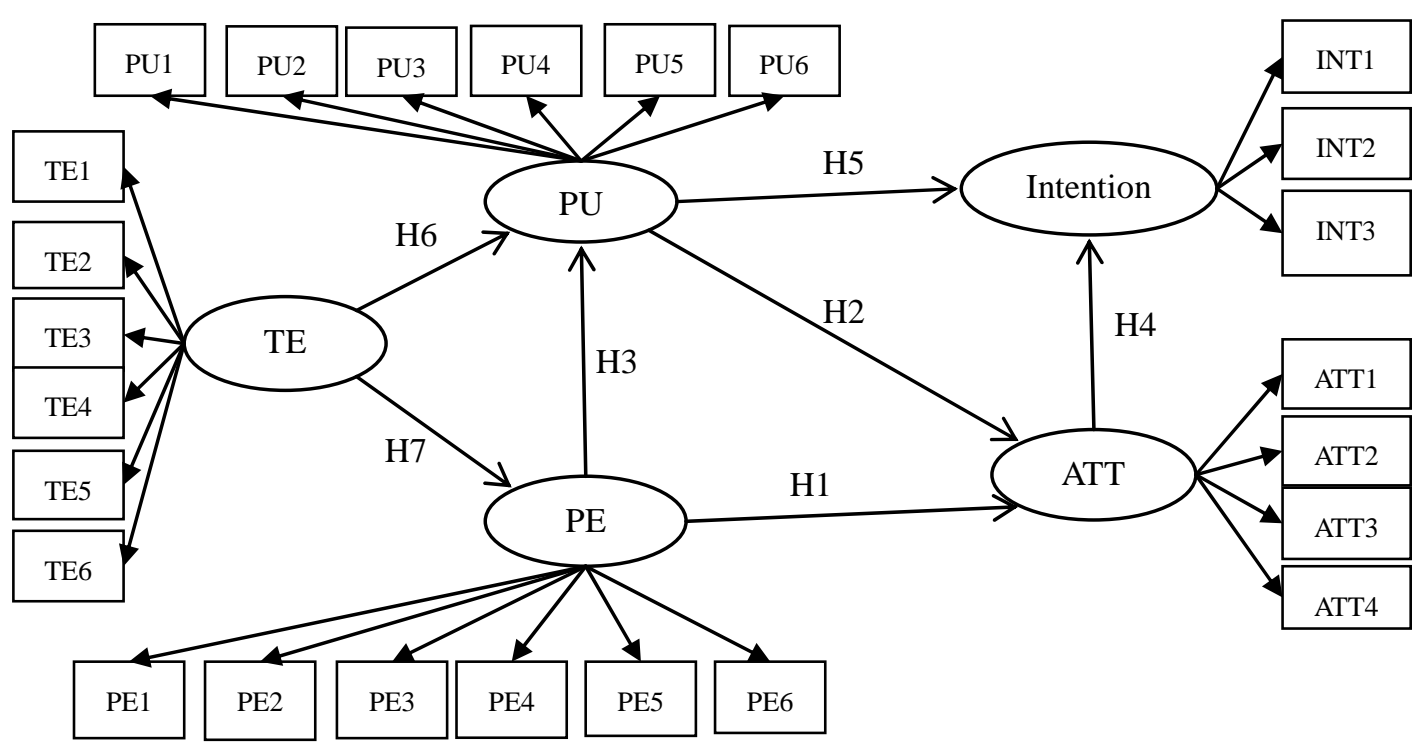

Figure 1. The research framework.

clinic fees in November and December in 2011. There 320 Taipei City Hospital patients in the research data.

This study was developed in a way that the model constructs in TAM were adapted to the context of using e-wallets for clinic fees. Scale items on the survey include those measuring perceived usefulness (PU), perceived ease of use (PE), a user's attitude toward using (ATT) and intention. The questionnaire contains no identifying information about the individual participants. A total of 320 Taipei City Hospital patients' feedbacks were collected. Some basic demographic information is collected, indicating approximately 188 females (58.75\%) and 132 males (41.25\%) in the sample population, most of them are 21 - 35 years old, and there are 196 patients in this age Interval (See Table 1).

The questionnaires of perceived usefulness (PU) are as follow:

1) I can easily complete the payment of clinic fees with Taipei Easy Card.

2) I can make the efficient completion of the payment of clinic fee with Taipei Easy Card.

3) Taipei Easy Card to satisfy payment of the demand for clinic fees.

4) Taipei Easy Card makes rapid completion of the payment of clinic fees.

5) Taipei Easy Card can reduce the time I wait for the payment of medical fees.

6) Taipei Easy Card makes the payment of medical expenses easier.

The questionnaires of perceived easiness of use (PE) are as follow:

1) When I pay the clinic fee with an error occurs, I can easily corrected it.

2) It is easy to understand how to use the Taipei Easy
Table 1. Data summarize.

\begin{tabular}{cccc}
\hline & & Frequency & Percent (\%) \\
\hline \multirow{2}{*}{ Gender } & Male & 132 & 41.25 \\
& Female & 188 & 58.75 \\
& $\sim 20$ & 23 & 7.18 \\
& $21-25$ & 78 & 24.38 \\
& $26-30$ & 60 & 18.75 \\
& $31-35$ & 58 & 18.13 \\
& $36-40$ & 26 & 8.12 \\
& $41-45$ & 29 & 9.06 \\
& $46-50$ & 16 & 5.00 \\
& $51 \sim$ & 30 & 9.38 \\
\hline
\end{tabular}

Card to pay clinic fees.

3) Remember how to use the Taipei Easy Card to pay clinic fees is easy for me.

4) It is easy to understand the process of how to pay clinic fees with Taipei Easy Card.

5) The process of the payment of the clinic fee with Taipei Easy Card, the staff gave the relevant assistance.

6) On the whole, it is very easy to use the Taipei Easy Card to pay clinic fees for me.

The questionnaires of the user's attitude toward using (ATT) are as follow:

1) It is a good idea that the pay clinic fees with Taipei Easy Card.

2) It is a wise decision that payment clinic fees with 
Taipei Easy Card.

3) It is good that pay clinic fees with Taipei Easy Card.

4) Overall, pay clinic fees with Taipei Easy Card is a positive attitude for me.

The questionnaires of Intention (INT) are as follow:

1) If I have a chance, I would pay the clinic fees with Taipei Easy Card.

2) The future I will likely pay the clinic fees with Taipei Easy Card.

3) I would pay the clinic fees with Taipei Easy Card more again.

The questionnaires of prior information technology experience (TE) are as follow:

1) I often use the word processing software (such as MS-Word).

2) I often use digital computing software (such as MS-Excel).

3) I often use presentation software (Such as MS-PowerPoint).

4) I can quickly find the information that I need on the network.

5) I often read the news and information on the Internet.

6) I often e-mail.

There are 5 parts in the research questionnaire with 5 scales (Likert scale). The questionnaire of PU, PE, ATT, Intention and IFE in this study are modified from David's study [3]. All variables exhibit a high level of reliability with the Cronbach's alpha values (Table 2) exceeding the recommended 0.6 [11]

\subsection{Model Testing}

The structural model is investigated using Mplus 6.1. Path analysis is performed on the model using standardized maximum likelihood estimation. The path analytic method offers the advantage of testing the overall model fit with multiple endogenous variables as in the model as well as individual a priori hypotheses.

The likelihood ratio chi-square test assesses the overall model fit. Chi-square per degree of freedom (CMIN/DF), the relative Chi-square, is 2.964, satisfying the recom-

Table 2. Scale reliability.

\begin{tabular}{ccc}
\hline Scale & N of Items & Cornbach's Alpha \\
\hline PU & 6 & 0.954 \\
PE & 6 & 0.893 \\
ATT & 4 & 0.964 \\
Intention & 3 & 0.949 \\
TE & 6 & 0.947 \\
\hline
\end{tabular}

mend $<5$ criterion for a good fit. The root mean square error of approximation (RMSEA) is 0.078 , and it is smaller than 0.08. The CFI is 0.936 and TLI is 0.929 , and they are all larger than 0.9 . The SRMR is 0.07 , and it is smaller than 0.08 . Thus the overall model has a good fit.

The results of correlation coefficient was as Table 3 . It could be found that square of AVE are between 0.933 to 0.780 . They are large than other ration in the table.

\section{RESULTS}

Correlations among the variables are illustrated in Figure 2. This model explains $81.3 \%$ of the variance in attitude and $34.7 \%$ of the variance in intention. The kurtosis index of this model is 130.407 , and it is below 650 (the units of observer variables the units of observer variables+2) [12]. So it is follow the multivariate rule.

Results indicate most of the relationships in the proposed model are statistically significant and in the predicted directions. Each observed variables influence with two ways: direct effect and indirect effect, and the total effect is the sum of direct effect and indirect effect. The Main effect of most of these observed variables is direct effect, but the information technology experience with the perceived usefulness. Seven hypotheses are supported at $\mathrm{p}<0.05$. Table 4 is the results of hypothesis testing.

\section{CONCLUSIONS}

Findings of this study provide evidence that TAM is an applicable model in examining factors influencing users' attitudes of using new technology and behavioral intentions in relation to pay clinic fees with e-wallet, such as Taipei Easy Card.

In this study, it could be finding that the perceived usefulness, the perceiver ease of use is positively associated with users' attitude toward using, and the perceiver ease of use is positively associated with the perceived usefulness. It means the useful and easily operation of payment clinic fees with e-wallet products (such as Taipei Easy Card) is very important for the users. Be-

Table 3. Results of correlation coefficient.

\begin{tabular}{cccccc}
\hline & PU & PE & ATT & Intention & Trust \\
\hline PU & 0.881 & & & & \\
PE & $0.648^{*}$ & 0.780 & & & \\
ATT & $0.534^{*}$ & $0.512^{*}$ & 0.933 & & \\
Intention & $0.303^{*}$ & $0.251^{*}$ & $0.657^{*}$ & 0.797 & 0.868 \\
TE & $0.465^{*}$ & $0.376^{*}$ & $0.452^{*}$ & $0.289^{*}$ & 0 \\
\hline${ }^{*} \mathrm{P}$-value $<0.05$. & & & & &
\end{tabular}




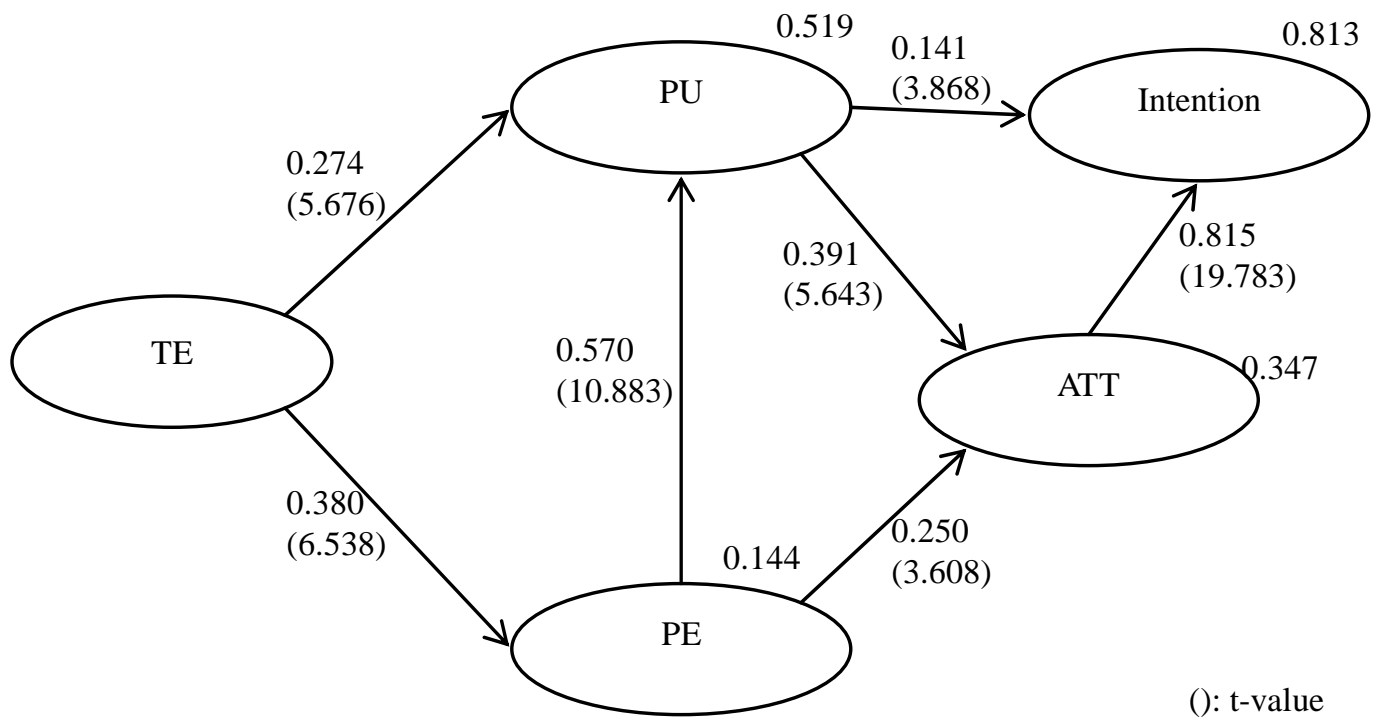

Figure 2. Structural model with inter-construct correlations.

Table 4. Results of hypothesis testing.

\begin{tabular}{|c|c|c|c|c|c|}
\hline & Path & Direct effect (p-value) & Indirect effect (p-value) & Total effect & Support \\
\hline H1 & PU $\rightarrow$ ATT. & $\begin{array}{c}0.391 \\
(<0.000)\end{array}$ & - & 0.391 & Yes \\
\hline $\mathrm{H} 2$ & $\mathrm{PE} \rightarrow$ ATT. & $\begin{array}{c}0.250 \\
(<0.000)\end{array}$ & $\begin{array}{c}0.223 \\
(<0.000)\end{array}$ & 0.473 & Yes \\
\hline H3 & $\mathrm{PE} \rightarrow \mathrm{PU}$. & $\begin{array}{c}0.570 \\
(<0.000)\end{array}$ & - & 0.570 & Yes \\
\hline $\mathrm{H} 4$ & ATT $\rightarrow$ Intention. & $\begin{array}{c}0.815 \\
(<0.000)\end{array}$ & - & 0.815 & Yes \\
\hline H5 & PU $\rightarrow$ Intention. & $\begin{array}{c}0.141 \\
(<0.000)\end{array}$ & $\begin{array}{c}0.319 \\
(<0.000)\end{array}$ & 0.460 & Yes \\
\hline H6 & $\mathrm{TE} \rightarrow \mathrm{PU}$. & $\begin{array}{c}0.274 \\
(<0.000)\end{array}$ & $\begin{array}{c}0.491 \\
(<0.000)\end{array}$ & 0.491 & Yes \\
\hline $\mathrm{H} 7$ & $\mathrm{TE} \rightarrow \mathrm{PE}$. & $\begin{array}{c}0.380 \\
(<0.000)\end{array}$ & - & 0.380 & Yes \\
\hline
\end{tabular}

sides, the easier for e-wallet using, the more people think it is usefulness. This suggestion is the same as the point at issue of Davis [3]. The users' attitude toward using is positively associated with the intention using.

For the personal prior experience, the information technology experience is positively associated with perceived usefulness and the perceiver ease of use, these results are the same as Davids [3].

\section{REFERENCES}

[1] Davis, F.D., Bagozzi, R.P. and Warshaw, P.R. (1989) User acceptance of computer technology: Comparison of two theoretical models. Management Science, 35, 982-1003. doi:10.1287/mnsc.35.8.982

[2] Bank for International Settlements (1996) Implication for central banks of the development of electronic money.

[3] Ajzen, I. and Fishbein, M. (1980) Understanding attitudes and predicting social behavior. Prentice-Hall, Englewood Cliffs.

[4] Mathieson, K. (1991) Predicting user intentions: Comparing the technology acceptance model with the theory of planned behavior. Information Systems Research, 2, 173-191.

[5] Szajna, B. (1996) Empirical evaluation of the revised technology acceptance model. Management Science, 42, 85-92. doi:10.1287/mnsc.42.1.85

[6] Gefen, D., Karahanna, E. and Straub, D.W. (2003) Trust and TAM in online shopping: An integrated model. MIS Quarterly, 27, 51-90.

[7] Hu, L.T. and Bentler, P.M. (1999) Cutoff criteria for fit indexes in covariance structure analysis: Conventional criteria versus new alternatives. Structural Equation Modeling, 6, 1-55. doi:10.1080/10705519909540118

[8] Peter, P.J. and Olson, J.C. (1990) Consumer behavior and marketing strategy. 2nd Edition, R. R. Donnelley, Chicago. 
[9] Downing, R.E., Moore, J.L. and Brown, S.W. (2005) The effects and interaction of spatial visualization and domain expertise on information seeking. Computers in Human Behavior, 21, 195-209. doi:10.1016/j.chb.2004.03.040

[10] Thompson, R.L., Higgins, C.A. and Howell, J.M. (1994) Personal computing: Towards a conceptual model of utilization. MIS Quarterly, 15, 125-142.

\section{doi:10.2307/249443}

[11] Nunnally, J.C. (1978) Psychometric theory. McGraw Hill, New York.

[12] Bollen, K.A. (1989) Structural equations with latent variables. Wiley, New York. 